\section{Aesthetic Plastic Surgery}

@ 1996 Springer-Verlag New York Inc.

\title{
Erratum
}

The illustrations appearing in the following article were published incorrectly in Aesthetic Plastic Surgery 20(1):53-57, 1996. The Editors now wish to make an apology to Dr. Michael I. Kulick of San Francisco, California for the inaccuracies made in the JanuaryFebruary, 1996 issue.

Despite accurate correcting of the page proofs by Dr. Kulick and by your Managing Editor, the excellent color photos in his article were interchanged during the printing process so that they appeared incorrectly in the issue; some of the preoperative photos became the postoperative photos and vice versa.

Your Editorial Staff, as well as Springer-Verlag, wish to correct this unfortunate error by reprinting Dr. Kulick's entire article in this issue in its original layout and pagination. The photographs, properly positioned here, should now do justice to the excellence of Dr. Kulick's surgery by revealing to the reader what he has accomplished by his surgery as described in the body of the article.

Blair O. Rogers, M.D.

Managing Editor 